\title{
NADİR BİR ŞEKER OLAN D-ALLÜLOZUN BESLENMEDE KULLANIM İMKANLARI VE ÜRETİM YÖNTEMLERİ
}

\author{
Hazal Özhanl1 ${ }^{1}$, Duygu Gizem Bilgin ${ }^{1}$, Ceren Mutlu ${ }^{1,2}$, Mustafa Erbaş ${ }^{1 *}$ \\ ${ }^{1}$ Akdeniz Üniversitesi Mühendislik Fakültesi Gıda Mühendisliği Bölümü, Antalya, Türkiye \\ ${ }^{2}$ Balıkesir Üniversitesi Mühendislik Fakültesi Gıda Mühendisliği Bölümü, Balıkesir, Türkiye
}

Geliş / Received: 30.12.2020; Kabul / Accepted: 05.05.2021; Online bask1 / Published online: 15.06.2021

Özhanll, H., Bilgin, D.G., Mutlu, C., Erbaş, M. (2021). Nadir bir şeker olan D-allülozun beslenmede kullanım imkanları ve üretim yöntemleri. GIDA (2021) 46 (4) 925-938 doi: 10.15237/gida. GD21010.

Özhanl, H., Bilgin, D.G., Mutlu, C., Erbass, M. (2021). D-allulose, a rare sugar, and its usage possibilities in nutrition and production methods. GIDA (2021) 46 (4) 925-938 doi: 10.15237/gida. GD21010.

ÖZ

Şekerler; duyusal olarak tatlı tada sahip, suda çözünürlügü yüksek ve molekül ağırlıkları düşük karbonhidratlar olarak tanımlanabilir. Doğada yüksek miktarda bulunan şekerler yaygın şekerler ve düşük miktarda bulunan şekerler ise nadir şekerler olarak adlandırllırlar. Nadir bir şeker olan D-allüloz, D-fruktozun 3. karbondan epimerik izomeridir. D-allüloz aynı zamanda D-glikoza eşdeğer tatlı tada, oldukça düşük enerji içeriğine ve glisemik indeks değerine sahip olması gibi özellikleri ile de gıda teknolojisinde kullanım potansiyeline sahip bir bileşendir. D-allülozun diğer endüstriyel şekerlere alternatif bir bileşen olarak kullanımı için doğal kaynakları yetersizdir. Bu nedenle D-allülozun diğer yaygın heksoz şekerlerden üretilmesi gerekmektedir. Dallülozun en genel üretim yöntemi; D-fruktozun, D-tagatoz 3-epimeraz veya D-allüloz 3-epimeraz enzimleri ile D-allüloza dönüştürülmesidir. Bu çalışmada; D-allülozun bazı özellikleri, sağlık üzerine etkileri, üretim yöntemleri ve gidalarda kullanım potansiyeli derlenmiştir.

Anahtar kelimeler: Şeker, nadir şeker, D-allüloz, D-psikoz, D-tagatoz 3-epimeraz

\section{D-ALLULOSE, A RARE SUGAR, AND ITS USAGE POSSIBILITIES IN NUTRITION AND PRODUCTION METHODS}

\begin{abstract}
Sugars are defined as carbohydrates with a sweet taste, high water solubility, and low molecular weight. Sugars found in high amounts in nature are classified as common sugars, sugars found in low amounts are classified as rare sugars. D-allulose, a rare sugar, is the C-3 epimeric isomer of Dfructose. D-allulose is also an ingredient having the potential for usage in food technology with its properties such as sweet taste equivalent to $\mathrm{D}$-glucose, very low energy content and glycemic index value. Natural resources are insufficient for $\mathrm{D}$-allulose to be used as an alternative ingredient to other industrial sugars. Therefore, D-allulose must be produced from other common hexose sugars. The most common production method of $\mathrm{D}$-allulose is the conversion of $\mathrm{D}$-fructose to $\mathrm{D}$-allulose by $\mathrm{D}$ tagatose 3-epimerase or $\mathrm{D}$-allulose 3-epimerase enzymes. In this study; some properties, effects on health, production methods and potential usage in foods of $\mathrm{D}$-allulose are reviewed.
\end{abstract}

Keywords: Sugar, rare sugar, D-allulose, D-psicose, D-tagatose 3-epimerase

\footnotetext{
${ }^{*}$ Yazışmalardan sorumlu yazar / Corresponding author

1): erbas@akdeniz.edu.tr (1): (+90) 2423106575

圆: (+90) 2423106306
}

Hazal Özhanlı; ORCID no: 0000-0002-9825-3916

Duygu Gizem Bilgin; ORCID no: 0000-0003-4162-1412

Ceren Mutlu; ORCID no: 0000-0003-4943-2798

Mustafa Erbaş; ORCID no: 0000-0002-9485-2356 


\section{GİRİ̧̧}

Karbonhidratlar, temel olarak karbon başına bir molekül suyun bağlanmasıyla oluşan organik hidratlardır. Ayrıca karbonhidratlar polihidroksi alkollerin aldehit veya keton türevleri olan bileşiklerin monomerik, oligomerik veya polimerik formları olarak da tanımlanabilir. İnsan beslenmesinde temel enerji kaynağı olan karbonhidratlar, glikanlar veya sakkaritler isimleriyle de bilinirler (Gil-Campos vd., 2015).

Şekerler ise; çoğunlukla 3 ila 6 arasında karbon atomuna sahip trioz, tetroz, pentoz ve heksoz grubu monosakkaritlerden veya bu monosakkaritlerin birkaçının glikozidik bağ ile birbirlerine bağlanması sonucu ortaya çıkan oligosakkaritlerden oluşan tatlı karbonhidratlar grubuna verilen genel bir isimdir. Ayrıca şekerler duyusal olarak tatlı tada sahip, suda çözünürlüğü yüksek ve molekül ağırlıkları düşük karbonhidratlar olarak da tanımlanabilir.

Doğada bulunan 36 adet pentoz ve heksoz formundaki monosakkaritlerden; D-glikoz, Dgalaktoz, D-mannoz, D-fruktoz, D-ksiloz, Driboz ve L-arabinoz doğal kaynaklarda yüksek miktarlarda bulunmaları nedeniyle yaygin monosakkaritler olarak adlandırılırken, diğerleri ise doğada oldukça az miktarlarda bulunmaları nedeniyle nadir monosakkaritler veya şekerler olarak adlandırilmaktadırlar.

Nadir şekerler, Uluslararası Nadir Şekerler Derneği (ISRS) tarafindan, doğada yaygın olmayan ve az miktarda bulunan monosakkaritler veya türevleri olarak tanımlanmaktadır (Zhang vd., 2017). Doğada iz miktarda bulunan D-alloz, D-allüloz, D-tagatoz, L-fruktoz ve L-sorboz gibi monosakkaritler en çok bilinen nadir şekerlerken bazı kaynaklar izomaltoz, izomaltuloz, trehaloz ve kojibioz gibi disakkaritleri de nadir şekerler arasında sinıflandırmaktadır (Van Laar vd., 2020).

Şekerler g1da endüstrisinde g1da maddelerinin tatlandırilmasi, donma veya erime noktalarının değiştirilmesi, renklendirilmesi ve korunması için yaygin olarak kullanılmaktadır. Ancak son yillarda özellikle işlenmiş gıdalar ile aşırı şeker tüketiminin obezite ve diyabet gibi hastaliklara neden olduğunun anlaşılması ile birlikte şekerlerin tüketimlerinin azaltılması veya ikame edilmesi yönünde araştırmalara ihtiyaç duyulmuştur (GilCampos vd., 2015). Nadir şekerler glikoz ve fruktoz gibi yaygin şekerler kadar duyusal tatlılığa sahip olmalarına rağmen enerji içerikleri yaygın şekerlere kiyasla oldukça düşük ve fizyolojik faydaları da yüksektir. Bu nedenlerle nadir şekerler g1da sektöründe kullanılan yaygin şekerlere ikame bileşenler olarak kabul edilmeye ve kullanılmaya başlanmıştır. Nadir şeker doğal kaynaklarının yetersiz olması nedeniyle nadir şekerlerin ticari üretimleri için çeşitli kimyasal, enzimatik ve mikrobiyolojik yöntemler kullanılmakta ve nadir şekerlerin üretimi hakkında gerçekleştirilen çalışmalar gittikçe artmaktadır (Mu vd., 2018).

Bu çalışmada nadir şekerlerden biri olan allülozun; genel özellikleri, vücutta metabolizasyonu, fizyolojik faydaları, gıdalarda kullanım potansiyeli ve üretim yöntemleri derlenmiştir.

\section{ALLÜLOZ VE BIYYOKIMYASAL ÖZELLİKLERİ}

Allüloz, $\mathrm{C}_{6} \mathrm{H}_{12} \mathrm{O}_{6}$ kapalı formülüne sahip bir ketoheksozdur. Eski adıyla psikoz olarak da bilinen D-allüloz, D-fruktozun karbon-3 epimeridir. CAS Numaras1 551-68-8 ve molekül ağırlı̆ı $180.156 \mathrm{~g} / \mathrm{mol}$ olan D-allüloz; beyaz, kristal, katı formda ve kokusuz bir bileşiktir. Sakkarozun \%70 eşdeğer tatlılığında olan allüloz, indirgen bir monosakkarit olduğu için gıdalarda enzimatik olmayan esmerleşme reaksiyonlarına katılabilmektedir (Patel vd., 2016; O'Charoen vd., 2015).

Uluslararası Nadir Şekerler Derneği tarafından 2014 yllinda düzenlenen Nadir Şekerler Sempozyumu'nda kimyasal adı D-ribo-2-heksüloz olan bu ketoheksozun, D-allozun izomeri olması ve $\mathrm{D}$-allitolün bir oksit ürünü olması nedeniyle isimlendirmede D-psikoz yerine D-allüloz isminin tercih edilmesi önerilmiştir (Yoshihara vd., 2017). Yine 2014 yılında allüloz, Gıda ve İlaç İdaresi (Food and Drug Administration, FDA) tarafindan Genel Olarak Güvenilir (GRAS) kategorisinde kabul edilmiş ve bir gida bileşeni veya gıda takviyesi olarak kullanılması onaylanmıştır (FDA, 2017). 


\section{ALLÜLOZUN BULUNDUĞU KAYNAKLAR}

Allüloz doğal bir bileşen olarak yalnızca Itea cinsine ait bitki türlerinde ve az miktarda buğdayda tespit edilmiştir (Oshima vd., 2006). Zeng vd., (2015) gerçekleştirdikleri bir çalışmada Itea virginica bitkisinin taze yapraklarında 82.3 $\mathrm{mg} / \mathrm{g}$ D-allüloz ve $21.2 \mathrm{mg} / \mathrm{g}$ allitol bulunduğunu, Itea oblonga Hand.-Mazz. ve Itea yunnanensis Franch bitkilerinin ise yaprak ekstraktlarında sirasiyla $38.4 \mathrm{mg} / \mathrm{g}$ ve $12.2 \mathrm{mg} / \mathrm{g}$ D-allüloz olduğunu bildirmişlerdir. Yine Japonya'da Zuina ismiyle bilinen Itea japonica Oliver bitkisi de doğal bir bileşen olarak allüloz içerip, üretebilmekte ve bu nedenle Zuina bitkisi, Japonya'da "Nadir Şeker Ağacı" olarak da isimlendirilmektedir (Hashii vd., 2015).

Allüloz Itea cinsine ait bitkilerin yanı sıra şeker pancarı melası ile işlenmiş şeker kamışında, esmer şekerde, akçaağaç şurubunda, kurutulmuş meyvelerde ve meyve sularında bulunabilmektedir (Oshima vd., 2006).

Sakkarozun hidrolizinden veya glikozun izomerizasyonundan elde edilen ticari D-glikoz ve D-fruktoz karışımlarında da D-allüloz az miktarlarda bulunabilmektedir (Han vd., 2018).
D-allüloz içeren nadir şeker şurubu, fonksiyonel bir tatlandırıcı olarak kabul edilmekte ve endüstriyel ölçekte yüksek fruktozlu mısır şurubunun alkali izomerizasyonu ile üretilmektedir. Nadir şeker şurubu, $\% 5$ oranında D-allüloz içermekte ve bu şurubun anti-obezite ve anti-diyabetik etkilere sahip olduğu bilinmektedir (Shintani vd., 2017).

Şekil 1'de verilen bazı gıda ürünlerinin ihtiva ettikleri allüloz miktarlar1 (FDA, 2017; Oshima vd., 2006) incelendiğinde sicaklık uygulamasının ürünlerin allüloz içeriği üzerinde etkili olduğu anlaşılmaktadır. İşlenmiş gıda ürünlerindeki allüloz miktarının, gıdanın başlangıçtaki fruktoz veya hidrolize uğrayan sakkaroz konsantrasyonuyla ve gıdanın işlenmesi esnasında uygulanan 1sıl işlem süre ve sıcaklı̆̆ ile yakından ilişkili olduğu bilinmektedir. Gıda ürünlerinin içerdiği fruktoz uzun süreli sıcaklık uygulaması ile allüloza epimerize olabilmektedir. Şeker kamışı suyu üzerinde yapılmış olan bir çalışmada 4 saatlik bir ısıl işlem sonrası şeker kamışı suyunun Dallüloz içeriğinin $0.1 \mathrm{mg} / 100 \mathrm{~mL}$ miktarından 2.9 $\mathrm{mg} / 100 \mathrm{~mL}$ miktarına yükseldiği bildirilmiştir (Oshima vd., 2006).

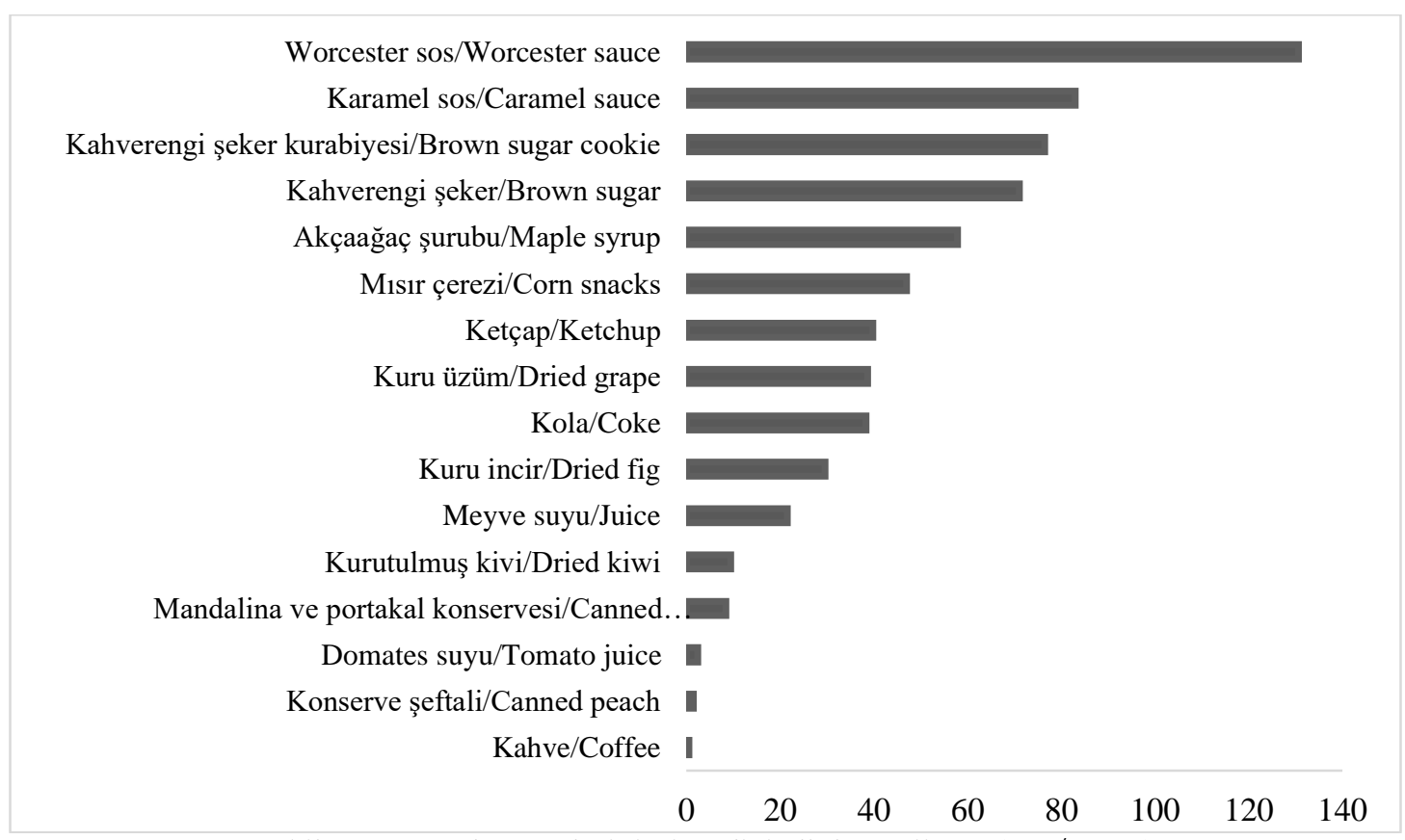

Şekil 1. Bazı g1da ürünlerinin içerdiği allüloz miktarı (mg/100 g) 


\section{ALLÜLOZUN METABOLİZASYONU VE TOKSİSITTESİ}

D-allüloz oldukça düşük kalori içeriğine $(<0.2$ $\mathrm{kcal} / \mathrm{g}$ ) ve glisemik indeks değerine sahip olduğu için, ideal bir sakkaroz ikamesi olarak gidalarda kullanılma potansiyeline sahiptir (Wee vd., 2018).

Iida vd., (2010) insanlarda allülozun metabolizması üzerine yaptıkları çalışmada, bireylerde allülozun $\% 70$ kadarının ince bağırsaktan absorbe edilip kan dolaşımına geçtiğini ve daha sonra metabolize edilmeden idrar ile uzaklaştırıldığını belirlemişlerdir. İnce bağırsak tarafından absorbe edilmeyen kısmının ise kalın bağırsakta, bağırsak bakterileri tarafından ihmal edilebilecek kadar düşük miktarda fermente edildiğini ve kalan allülozun ise dışkı ile uzaklaştığını tespit etmişlerdir.

Matsuo vd., (2002) gerçekleştirdikleri bir çalışmada farelere 14 gün boyunca tek doz halinde $8,11,14,17$ ve $20 \mathrm{~g} / \mathrm{kg}$ vücut ağırlı̆g miktarlarında D-allüloz uygulamışlar ve tüm farelerde bu dozların diyareye neden olduğunu ve yükssek dozda allüloz alımının bağırsak sistemi için zararlı olabileceğini bildirmişlerdir. Fareler üzerinde yapılan bir başka çalışmada ise 10 hafta uygulanmış bir diyette günlük $2 \mathrm{~g} / \mathrm{kg}$ vücut ağırlı̆̆ kadar allüloz uygulamasinın, allüloz uygulanmayan kontrol grubuna kiyasla fareler üzerinde olumsuz bir etki göstermediği belirlenmiştir (Kim vd., 2019).

Fruktoz için 14.7 ve eritritol için ise $15.3 \mathrm{~g} / \mathrm{kg}$ olan $\mathrm{LD}_{50}$ değeri, $\mathrm{D}$-allüloz için fare deneyleriyle $16.3 \mathrm{~g} / \mathrm{kg}$ olarak belirlenmiştir (Matsuo vd., 2002). FDA'nın toksisite derecelendirme çizelgesine göre, en düşük toksisite derecesi olan nispeten zararsız kategorisinde olması nedeniyle D-allüloz gida ürünlerine sakkaroz ikamesi olarak farklı miktarlarda eklenebilmektedir (Bilal vd., 2018).

FDA 2019 y1lında D-allülozu; kalori içeriğinin çok düşük olması, insan vücudunda metabolize edilememesi ve glisemik indeks değerinin düşük olması nedenleriyle diğer şekerlerden farklı olduğu için gida etiketlerinde şekerler kategorisinde sınıflandırılmayacağını açılamışıtı (FDA, 2019).

\section{ALLÜLOZUN SAĞLIK ÜZERINNE ETKILLERİ}

D-fruktozun 3. karbonundan epimeri olan Dallüloz, sağlık üzerinde olumlu etkileri olan bir monosakkarittir. D-allüloz kan şeker düzeyini yükseltmemesinin yanı sıra düşürücü bir etkiye de sahiptir (Iwasaki vd., 2018). D-allülozun kan şekeri düzeyini düşürücü etkisi iki mekanizma ile açıklanabilmektedir. Birinci mekanizmaya göre; in vitro ve in vivo çalışmalarla gösterilmiştir ki Dallüloz ince bağırsakta $\alpha$-glikozidazın aktivitesini inhibe ederek, glikoz emiliminin azalmasını sağlamaktadır. İkinci mekanizmaya göre ise; kandaki glikozun karaciğerdeki glikojene dönüşümünü teşvik eden glikokinaz enziminin faaliyetini destekleyerek kan şeker seviyesini düşürmektedir (Shintani vd., 2017). Gerçekleştirilen bir araştırmada 8 hafta boyunca D-allülozla beslenen farelerde, D-allülozun karaciğer glikojenini arttırdığ1 tespit edilmiştir. Aynı zamanda allülozla beslenen farelerin, kontrol grubuna kiyasla kan şekeri düzeylerinin düşük olduğu ve insülin konsantrasyonunun ise allülozla beslenen farelerde anlamlı bir şekilde yüksek olduğu bildirilmiştir (Matsuo ve Izumori, 2006).

Ayrıca D-allülozun, yapı benzerliği nedeniyle Dglikoz ve D-fruktozun sindirim kanalında taşınmasında rol alan proteinlere bağlanarak onların emilimini indirekt olarak azaltıcı bir etkiye sahip olduğu ve bu yolla da insan vücudunda glisemik indeksin azalmasina katkıda bulunduğu rapor edilmiştir (Hossain vd., 2015). Bazı araştırmalarda da D-allülozun diğer karbonhidratlara kıyasla besin alımını baskılayıcı etkide olduğu ve vücutta yağ birikimini azalttı̆̆ bildirilmiştir (Kimura vd., 2017; Matsuo ve Izumori, 2006).

Çeşitli çalışmalar D-allülozun anti-hiperlipidemik aktiviteye sahip olduğunu doğrulamıştır. Dallülozun lipid metabolizması üzerine etkilerinin belirlendiği bir çalışmada fareler 4 hafta boyunca ögün miktarının \%3’ü kadar D-allüloz içeren ve içermeyen misır nişastası ile beslenmiştir. Çalışma ile D-allüloz diyetinin lipogenezde rol alan karaciğer enzimi aktivitesini baskıladığı, yağ asidi oksidasyonunu ve 24 saatlik enerji harcamasını ise arttırdığ1 tespit edildiğinden kilo yönetimini 
kontrol etmede uygun olduğu bildirilmiştir (Nagata vd., 2015). Yine farelerde yapılan bir çalışmada 16 hafta boyunca uygulanan yüksek yağlı diyette sakkaroza ikame olarak öğünde ağırlıkça \%5 D-allüloz takviyesinin ince bağırsakta yağ emilimini azalttığ1 ve yağ kullanımını artırdığ belirlenmiştir (Han vd., 2016).

D-allüloz takviyesinin, yüksek yağlı bir diyetin lipid metabolizması üzerindeki etkilerini hafifletip hafifletmediğini belirlemek üzere yapılan bir araştırmada, 8 hafta boyunca farelere D-allüloz takviyesi olan ve olmayan diyetler uygulanmıştır. Allüloz içeren diyet grubunun vücut yağ dokusunun, karaciğer ağırlıklarının ve açlık kan glikoz seviyesinin kontrol grubuna göre daha düşük düzeyde olduğu tespit edilmiştir. $\mathrm{Bu}$ sonuçlar D-allülozun genel lipid metabolizmasını geliştirebildiğini ve vücutta yağ birikmesini önlemek için fonksiyonel bir gida bileşeni olarak kullanılabileceğini göstermiştir (Do vd., 2019).

Allülozun gidalarla tüketiminin insan sağllğ1 üzerine etkileri hakkında 121 yetişkin bireye yapılan bir çalışmada ise 12 hafta boyunca günde 2 öğün uygulanan diyette 4 ve $7 \mathrm{~g}$ allüloz alımının deneklerde anormal bir etkiye veya klinik bir soruna neden olmadiğı tespit edilmiştir (Han vd., 2018). Özgür ve Uçar, (2019) tarafindan karbonhidrat ve yağ metabolizmasının bozulduğu bazı endokrin hastalıklarında alternatif bir tedavi seçeneği olarak diyette D-allülozun kullanılabileceği ve bu nedenle de D-allüloz içeren gida ürünlerinin geliştirilerek, tüketime sunulmasının yararlı olacağı bildirilmiştir.

\section{ALLÜLOZUN GIDALARDA KULLANIMI}

D-allüloz genel olarak firıncilık ürünleri, alkolsüz içecekler, dondurma, yoğurt, çorba ve soslarda kullanılmasinın yanı sıra kivam arttırıcı ve stabilize edici bir ajan olarak işlenmiş et ürünlerinde ve tıbbi ilaçlarda da kullanılmaktadır (FDA, 2017; Jiang vd., 2020). Tatlı tad1, düşük kalorisi, yüksek higroskopisitesi, çok düşük glisemik indeksi, antikaryojenik etkisi ve diyareye neden olmayışı gibi özellikleriyle D-allüloz çeşitli şekerleme ürünlerine de ilave edilebilmektedir (Barkalow vd., 2018).
D-allülozun gıda endüstrisinde kullanımı üzerine yapılmış çeşitli çalışmalarda, ilave edildiği gıdada retrogradasyonu geciktirici ve jel oluşumunu destekleyici etkide bulunduğu ve isıl işlem gören gidalarda D-fruktoz ve D-glikoza göre Maillard reaksiyonuna daha düşük düzeyde katıldığı tespit edilmiştir (Hossain vd., 2015; Ilhan vd., 2020). Allüloz, puding gibi jel gıdalara ilave edildiğinde gidanın viskoelastik yapısını ve kırılma direncini geliştirip, jelde proteinlerin çapraz bağlanmasını teşvik etmektedir (Hadipernata vd., 2017).

Tavuk sosisine \%2.5 oraninda sakkaroz ikamesi olarak ilave edilen allülozun, kontrol örneğine göre; sosis viskozitesini $\% 10$ arttırdığı, dondurulup çözülmüş sosislerin reolojik özelliklerinin \%19 daha iyi olduğu ve ürünün su tutma kapasitesini ve elastikiyetini koruduğu belirlenmiştir (Hadipernata vd., 2016). Allülozun dondurulup çözülmüss sosislerdeki hasar önleyici bu etkileri dondurulmuş gidalara uygulanmasının faydalı olabileceğini göstermektedir.

Ayrıca allüloz bitki koruma alanında da bakteriyel yanma gibi ekin hastalıklarına karşı direnç sağlayıcı olarak kullanılabilmektedir (Mao vd., 2020; Yoshihara vd., 2017).

\section{ALLÜLOZUN ÜRETİMİ Allülozun Kimyasal Üretimi}

Allüloz doğada nadir bulunan bir şeker olması nedeniyle kimyasal olarak yaygin bulunan şekerlerden allülozun üretilmesi için farklı yöntemler geliştirilmiştir. Bu yöntemlerden biri; D-fruktozu molibdat iyonlarının katalitik etkisi altında asidik çözeltide D-allüloza epimerize etmektir (Bilik ve Tihlárik, 1973). McDonald (1967) tarafindan gerçekleştirilen başka bir yöntemde ise; 3 kimyasal aşamada 1,2:4,5-di-Oisopropiliden- $\beta$-D-fruktopiranozdan allüloz sentezlenmiştir. Diğer bir kimyasal üretimde ise; D-fruktoz, etanol ve trietilamin içerisinde kaynatılarak D-allüloz elde edilmiştir (Doner, 1979). Fakat tüm bu üretim yöntemlerinin karmaşık saflaştırma aşamaları gerektirmesi, kimyasal atık ve yan ürün oluşumu gibi dezavantajlarının olması nedenleriyle $\mathrm{D}$-allülozun büyük ölçekli üretimi maliyetli ve düşük verimli olmaktadır. 


\section{Allülozun Mikrobiyolojik ve Enzimatik Üretimi}

Son zamanlarda allüloz gibi nadir şekerlerin fizyolojik etkileri ve faydalarına dair yapılan çalışmalar artmıs ve bu durum doğada az miktarda rastlanan bu şekerlerin seri üretim yöntemlerinin araştırlmasına yol açmışır. Allülozun mikrobiyolojik yöntemler kullanılarak üretiminin, kimyasal sentez yöntemlerine göre daha çevre dostu olduğu ve kullanilan enzimatik tekniklerin orta yoğunlukta reaksiyon şartları, yüksek verimlilik, spesifiklik ve sürdürülebilirlik gibi birçok avantaj sağladığ1 tespit edilmiştir (Zhang vd., 2017).

Nadir şekerlerin üretimi için geliştirilmiş bir yöntem ile uygun biyokatalizörler kullanılarak D- glikoz ve D-fruktoz gibi doğal ve ucuz heksozlardan, diğer tüm heksozların eldesi gerçekleştirilebilmektedir. Izumoring Stratejisi adı verilen bu yöntem, özellikle allülozun da dahil olduğu nadir ketoheksozların enzimatik üretiminde öncü bir yöntem haline gelmiştir. $\mathrm{Bu}$ yöntemde kullanılan biyokatalizörlerden ketoz 3epimeraz enzim gruplar1, serbest halde bulunan ketoheksozların 3. karbonunun geri dönüşümlü epimerizasyonunu katalize etmekte ve ketoheksozların enzimatik dönüşümünde oldukça kritik bir role sahip olmaktadır (Li vd., 2015; Mu vd., 2015). D-allülozun, D-fruktozdan ketoz 3epimeraz enzimleri araciliğı ile dönüşümü Şekil 2'de verilmiștir.<smiles>O=C(CO)C(O)C(O)C(O)CO</smiles>

D-fruktoz/D-fructose
Ketoz 3-epimeraz/ Ketose 3-epimerase

Şekil 2. D-fruktoz ve D-allülozun yapıları ve enzimatik dönüşümleri
D-fruktozun D-allüloza epimerizasyonunu katalize edebilen D-tagatoz 3-epimeraz (DTEaz, EC 5.1.3.31) ve D-allüloz 3-epimeraz (DAEaz, EC 5.1.3.30) enzimleri çeşitli mikroorganizmalardan kismen veya tamamen saflaştırilmış, rekombinant veya immobilize formda izole edilmiştir. 1993 yılında D-fruktozun C-3 konumunda D-allüloza epimerizasyonunu gerçekleştirebilen bir ketoz 3-epimeraz enzimi Pseudomonas cichorii ST-24 suşu kullanılarak karakterize edilmiş ve ilk defa rapor edilen bu enzimin seçici substratı D-tagatoz olduğu için Dtagatoz 3-epimeraz olarak isimlendirilmiştir (Itoh vd.,1994). Daha sonra Rhodobacter sphaeroides (Qi vd., 2017), Caballeronia fortuita (Li vd.,2019) ve Sinorbizobium sp. (Zhu vd., 2019) gibi çeşitli mikroorganizmalarda da DTEaz enzimi belirlenmiştir.

D-fruktozdan D-allüloz epimerizasyonunu katalize edebilen bir başka enzim olan D-allüloz 3-epimeraz ise ilk defa Agrobacterium tumefaciens mikroorganizmasından elde edilip, tanımlanmış ve bu enzimin seçici substratı $\mathrm{D}$-allüloz olduğu için D-tagatoz 3-epimeraz yerine D-allüloz 3epimeraz olarak isimlendirilmiştir (Kim vd., 2006). Devam eden araştırmalarda ise; Clostridium cellulobyticum (Mu vd., 2011), Ruminococcus sp. (Zhu vd., 2012), Clostridium scindens (Zhang vd., 2013a), Desmospora sp. (Zhang vd., 2013b), Clostridum sp. (Mu vd., 2013), Clostridium boltae (Jia vd., 2014), Treponema primitia (Zhang vd., 2016), Flavonifractor plautii (Park vd., 2016), Artbrobacter globiformis 
(Yoshihara vd., 2017), Agrobacterium sp. (Tseng vd., 2018), Dorea sp. (Zhang vd., 2015; Zhang vd., 2018), Sinorbirobium sp. (Zhu vd.,2019) gibi mikroorganizmalardan da DAEaz enzimi karakterize edilip, tanımlanmıştır. D-fruktozdan
D-allüloz üretiminde farklı suşlardan izole edilerek kullanılan bazı DTEaz ve DAEaz enzimlerinin biyokimyasal özellikleri karşılaştırmalı olarak Çizelge 1'de verilmiştir.

Çizelge 1. Allüloz üretiminde kullanılan enzimlerin biyokimyasal özelliklerinin karşılaştırılması

\begin{tabular}{|c|c|c|c|c|c|}
\hline Ketoz 3-epimeraz & $\begin{array}{c}\text { Optimum } \\
\text { Sicaklik }\left({ }^{\circ} \mathrm{C}\right)\end{array}$ & $\begin{array}{l}\text { Optimum } \\
\mathrm{pH}\end{array}$ & Aktivatör & $\begin{array}{l}\text { Denge } \\
\text { oran1 }^{a}\end{array}$ & Referanslar \\
\hline Agrobacterium sp. DAEaz & $55-60$ & $7.5-8.0$ & $\mathrm{Co}^{+2}$ & $30: 70$ & $\begin{array}{l}\text { (Tseng vd., } \\
2018)\end{array}$ \\
\hline $\begin{array}{l}\text { Agrobacterium tumefaciens } \\
\text { DAEaz }\end{array}$ & 50 & 8.0 & $\mathrm{Mn}^{+2}$ & $33: 67$ & $\begin{array}{l}\text { (Kim vd., } \\
\text { 2006) }\end{array}$ \\
\hline Clostridium bolteae DAEaz & 55 & 7.0 & $\mathrm{Co}^{+2}$ & $32: 68$ & (Jia vd., 2014) \\
\hline $\begin{array}{l}\text { Clostridium cellulolyticum } \\
\text { DAEaz }\end{array}$ & 55 & 8.0 & $\mathrm{Co}^{+2}$ & $32: 68$ & (Mu vd., 2011) \\
\hline Clostridium scindens DAEaz & 60 & 7.5 & $\mathrm{Mn}^{+2}$ & $28: 72$ & $\begin{array}{l}\text { (Zhang vd., } \\
\text { 2013a) }\end{array}$ \\
\hline Clostridium sp. DAEaz & 65 & 8.0 & $\mathrm{Co}^{+2}$ & $28: 72$ & (Mu vd., 2013) \\
\hline Desmospora sp. DAEaz & 60 & 7.5 & $\mathrm{Co}^{+2}$ & $30: 70$ & $\begin{array}{l}\text { (Zhang vd., } \\
\text { 2013b) }\end{array}$ \\
\hline Dorea sp. DAEaz & 70 & 6.0 & $\mathrm{Co}^{+2}$ & $30: 70$ & $\begin{array}{l}\text { (Zhang vd., } \\
\text { 2015) }\end{array}$ \\
\hline Ruminococcus sp. DAEaz & 60 & $7.5-8.0$ & $\mathrm{Mn}^{+2}$ & $28: 72$ & $\begin{array}{l}\text { (Zhu vd., } \\
\text { 2012) }\end{array}$ \\
\hline Treponema primitia DAEaz & 70 & 8.0 & $\mathrm{Co}^{+2}$ & $28: 72$ & $\begin{array}{l}\text { (Zhang vd., } \\
\text { 2016) }\end{array}$ \\
\hline Caballeronia fortuita DTEaz & 60 & 7.5 & $\mathrm{Co}^{+2}$ & $37.5: 62.5$ & (Li vd., 2019) \\
\hline Pseudomonas cichorii DTEaz & 60 & 7.5 & - & $20: 80$ & $\begin{array}{l}\text { (Itoh vd., } \\
\text { 1994) }\end{array}$ \\
\hline $\begin{array}{l}\text { Rhodobacter sphaeroides } \\
\text { DTEaz }\end{array}$ & 40 & 9.0 & $\mathrm{Mn}^{+2}$ & $23: 77$ & $\begin{array}{l}\text { (Zhang vd., } \\
\text { 2009) }\end{array}$ \\
\hline
\end{tabular}

a Sirasıyla D-allüloz ve D-fruktoz oranları

Allüloz üretiminde kullanılan enzimlerin Dallüloz ve D-fruktoz arasindaki denge oranları, endüstriyel epimerizasyon uygulamas1 bakımından oldukça önemli bir parametre olup bu denge oranı kullanılan enzimlere göre farklilık göstermektedir (Jia vd., 2014; Kim vd., 2006; Li vd., 2019; Mu vd., 2011). DTEaz ve DAEaz enzimlerinin genel olarak aktivite gösterdikleri optimum sicakliklar $50-70^{\circ} \mathrm{C}$ ve optimum $\mathrm{pH}$ değerleri 7.0-9.0 arasında değişmektedir. Enzimlerin moleküler ağırlıklarının ise; monomerik yapıdaki enzimler için yaklaşı 33
$\mathrm{kDa}$, dimerik enzimler için yaklaşık $64 \mathrm{kDa}$ ve tetramerik enzimler için ise $130-139 \mathrm{kDa}$ arasinda olduğu bildirilmiştir (Jia vd., 2014; Li vd., 2019; Mu vd., 2013; Zhang vd., 2018). Çizelge 1'de verilen DAEaz enzimlerinin tamamı D-allüloz için en iyi substrat seçiciliği gösterirken, $P$. cichorii DTEaz ve $C$. fortuita DTEaz D-tagatoz için ve $R$. sphaeroides DTEaz ise D-fruktoz için en yüksek substrat seçiciliğini göstermektedir (Itoh vd., 1994; Li vd., 2019; Zhang vd., 2009). 
D-fruktozun D-allüloza izomerizasyonunda DTEaz ve DAEaz enzimlerinin aktivitesi $\mathrm{Co}^{+2}$ ve $\mathrm{Mn}^{+2}$ gibi metal iyonlarının varlığında önemli derecede artmaktadır. D-fruktozdan D-allüloz eldesinde $A$. tumefaciens DAEaz ve R. sphaeroides DTEaz enzimleri sistemde metal iyonu olmadan aktivite gösterebilirken, sisteme $\mathrm{Mn}^{+2}$ iyonu ilave edildiğinde enzimlerin aktiviteleri kayda değer şekilde artmaktadır (Kim vd., 2006; Zhang vd., 2009). C. cellulobticum DAEaz ve C. scindens DTEaz ortamda sirasiyla $\mathrm{Co}^{+2}$ ve $\mathrm{Mn}^{+2}$ iyonu olmadan aktivite gösterememektedir (Mu vd., 2011; Zhang vd., 2013a). P. cichorii den elde edilen DTEaz enzimi ise aktivite için herhangi bir metal iyonuna ihtiyaç duymamaktadır (Itoh vd., 1994).

D-allüloz eldesinde doğal mikrobiyal kaynaklardan izole edilen enzim, enzimin yarılanma ömrünün kısa olması, düşük stabiliteye sahip olmas1, uygulama sonrasi enzim geri kazanımının zor olması ve yeniden kullanımında aktivite kayb1 gözlenmesi gibi nedenlerle endüstriyel uygulama için yeterli olmamaktadır (Dedania vd., 2020; Ran vd., 2019). Bu nedenle araştırmalar çoğunlukla DTEaz enzim ailesinin tanımlanıp, izole edildiği doğal suşlar yerine gen ekspresyonu ile elde edilen rekombinant suşlar ile yapilmıştır. Takeshita vd., (2000) P. cichoriiden DTEaz enzimini kodlayan genin farklı bir konak olan rekombinant Escherichia colìye eksprese edilmesi yoluyla üretip, saflaştırdıkları DTEaz enzimini D-fruktozdan D-allüloz üretiminde immobilize şekilde kullanarak 60 gün sonunda 20 $\mathrm{kg}$ saf D-allüloz ürettiklerini bildirmişlerdir. Ayrica rekombinant E. coli tarafindan üretilen enzim miktarının, $P$. cichorii ST-24'ten elde edilen enzim miktarının yaklaşık 100 katı olduğu belirlenmiştir.

Son zamanlarda D-allüloz üretiminde DTEaz enzimlerini eksprese etmek için E. coli yerine Bacillus subtilis veya çeşitli mayaların kullanımı araştırılmıştır (Chen vd., 2016; Yang vd., 2018). Yang vd., (2018) A. tumefaciens DAEaz genini Kluyveromyces marxianus'a eksprese ederek gerçekleştirdikleri araştırmada $55^{\circ} \mathrm{C}$ sıcaklıkta 12 saatte $750 \mathrm{~g} / \mathrm{L}$ D-fruktozdan, $190 \mathrm{~g} / \mathrm{L}$ D-allüloz elde etmişlerdir. Zhang vd., (2020) Rhodopirellula baltica SH 1 suşundan klonladıkları DTEaz kodlayan geni, B. subtilis'e eksprese ederek elde ettikleri DTEaz enzimi ile D-fruktozdan \%56.26 oranıyla D-allüloz üretmişlerdir. Aynı zamanda rekombinant DTEaz enzimi, elma posas1 hidrolizatına uygulanarak ağırlıkça \%25.86 dönüşüm oranı ile D-allüloz eldesi sağlanmıştır. Rekombinant DTEaz ve DAEaz enzimleri ile Dallüloz üretiminde hammadde olarak meyve-sebze atıkları kullanılabileceği gibi şeker pancarı melası veya misir gibi gida maddeleri de kullanılabilmektedir (Juneja vd., 2019; Patel vd., 2016; Patel vd., 2018; Song vd., 2017a; Song vd., 2017b)

Enzimlerin immobilizasyon ile kullanılmasi; enzimlerin tekrar kullanımı, stabilitesi ve aktivitesi açısından serbest olarak kullanımlarına göre çok daha etkili bir yöntemdir (Dedania vd., 2017). Rekombinant $A$. tumefaciens DAEaz enziminin serbest halde kullanımı ile D-allülozun Dfruktozdan üretiminde elde edilen $\mathrm{D}$-allüloz ve $\mathrm{D}$ fruktoz denge oranı sirasiyla 33:67 iken, $A$. tumefaciens DAEaz enzimi titanyum dioksit yüzeyinde immobilize halde kullanıldığında bu oran 36:64 olarak belirlenmiş ve enzimin yarılanma ömrünün ise immobilize halde kullanıldığında arttığı bildirilmiştir (Dedania vd., 2020; Kim vd., 2006).

Izumoring Stratejisine göre D-allüloz doğrudan D-glikoz çözeltisine DTEaz enzimi ve D-glikoz izomeraz (DGIaz, EC 5.3.1.5) enziminin birleştirilerek uygulanması ile ara basamak ile oluşturulan D-fruktoz kullanılarak da üretilebilmektedir (Li vd., 2015). Chen vd., (2017) gerçekleştirdikleri bir çalışmada DGIaz ve $A$. tumefaciens DAEaz genlerini E. coli MG1665 suşuna eksprese ederek elde ettikleri enzimi $40^{\circ} \mathrm{C}$ sıcaklıkta $24.5 \mathrm{~g} / \mathrm{L}$ D-glikoz içeren selüloz hidrolizatına ve $26.4 \mathrm{~g} / \mathrm{L} \mathrm{D}$-glikoz içeren mikroalg hidrolizatına uygulamışlar ve sırasıyla 1.42 ve $1.69 \mathrm{~g} / \mathrm{L}$ konsantrasyonlarında D-allüloz üretimi gerçekleştirmişlerdir.

\section{ALLÜLOZUN SAFLAŞTIRILMASI}

Yapılan çalışmalarda D-allülozun izolasyonu ve saflaştırılması için genellikle iki farklı yöntem kullanılmıştır. $\mathrm{Bu}$ yöntemlerden biri olan iyon değiştirici reçine matrisi ve simüle edilmiş 
hareketli yatak kromatografisi kullanımı üretim verimliliği yüksek olmasına rağmen, maliyetli bir yöntem olması ve karmaş1k ekipman gerektirmesi gibi dezavantajlarr bulunan bir teknolojidir. Li vd., (2018b) yaptıkları bir çalışmada rekombinant DAEaz enziminin katalizörlügünde elde edilen Dfruktoz ve $\mathrm{D}$-allüloz karışımını simüle edilmiş hareketli yatak kromatografisinden geçirerek $\% 98.5$ saflık oranında $\mathrm{D}$-allüloz üretimi sağlamışlardır. Gerçekleştirilen bir başka çalışmada ise D-allüloz ve D-fruktoz çözeltisi, glikoz oksidaz ve glikoz izomeraz enzimlerini içeren sürekli karıştırmalı bir reaktöre alınarak Dfruktoz glukonik aside dönüştürülmüş ve anyon değişim reçinesi kullanılarak da glukonik asit uzaklaştırılmış ve \%091.2 saflıkta D-allüloz elde edilmiştir (Li vd., 2018a).

D-allülozun izolasyonu ve saflaştırılması için kullanılan ikinci yöntem ise D-fruktoz ve Dallülozun karışım halinde bulunduğu sisteme maya ilavesi ile fruktozun etanole dönüştürülüp, buharlaştırılarak ortamdan uzaklaştırılmasıdır. Takeshita vd., (2000) D-allüloz ve D-fruktozdan oluşan karışımı aerobik şartlarda firıncı mayası ile fermantasyona tabi tutarak D-fruktozun tüketimini etanol üretimi ile sağlamışlardır. Fermantasyon sonucu oluşan etanol buharlaştırma işlemi ile uzaklaştırıldıktan sonra elde edilen şurup, tekrar etanolle kaynatılarak Dallülozun kristal olarak ayrılması sağlanmıştır. Bu saflaştırma işleminin zaman ve maliyet bakımından önemli avantajları olmasının yanı sıra şuruptan D-allüloz üretim veriminin $\% 85$ olduğu bildirilmiştir. $\mathrm{Bu}$ yöntemin avantajları arasında düşük hammadde maliyeti, atık oluşumunun azaltılması, enerji tüketiminin düşürülmesi, şeker veriminin iyileştirilmesi ve iyon değişim reçinesi uygulamasına göre daha çevre dostu bir uygulama olması sayılabilir.

\section{SONUÇ}

Dünyada kısıtlı bir miktarda üretilen ve üzerinde az sayıda araştırma yapılmış olan D-allülozun ülkemizde üretimi olmayıp, üzerinde yapılan araştırmalar ise oldukça sınırlıdır. Günümüzde enzimatik yöntemlerle üretilmekte olan D-allüloz, üretiminde kullanılan enzimlerin yetersiz aktivitesi ve geri kazanımının zor olmasi gibi nedenlerle üretim maliyeti yüksek, verimliliği ise oldukça düşük bir nadir şekerdir. $\mathrm{Bu}$ nedenlerle $\mathrm{D}$ allülozun endüstriyel üretiminin geliştirilmesi için yeni fiziksel, kimyasal, biyokimyasal ve mikrobiyolojik yöntemlerin araştırılması ve mevcut üretimde kullanılan yöntemlerin geliştirilerek optimize edilmesine yönelik araştırmaların yapılması önemlidir.

Bu çalışma ile; D-allülozun düşük enerji içeriğine ve vücutta olumlu fizyolojik etkilere sahip olduğu ve bu yönleriyle de yaygin şeker ve yapay tatlandırıcilara önemli bir alternatif oluşturduğu ortaya konmuştur. Bu nedenle de gida ve ilaç endüstrisinde düşük enerji içerikleri ve olumlu fizyolojik etkileriyle yüksek bir kullanım potansiyeline sahip olan nadir şekerlerin ve özellikle de D-allülozun üretim ve kullanımına yönelik araştırmaların artırılması gerektiği sonucuna varılmıștır.

\section{ÇIKAR ÇATIŞMASI BEYANI}

Bu makale ile ilgili olarak yazarların, başka kişiler ve/veya kurumlar ile çıar çatışması bulunmamaktadır.

\section{YAZAR KATKILARI}

Tüm yazarlar makalenin yapilmasında, yazılmasında ve yayınlanmasında eşit katkı sağlamışlardır. Makalenin hazırlanmasında başka kişi ve/veya kurumların katkısı yoktur.

\section{KAYNAKLAR}

Barkalow, D.G., Hsu, C., Haseleu, A., Stawski, B.Z. (2018). Confections containing allulose. Patent US-20180271112-A1.

Bilal, M., Iqbal, H.M.N., Hu, H., Wang, W., Zhang, X. (2018). Metabolic engineering pathways for rare sugars biosynthesis, physiological functionalities, and applications-a review. Crit Rev Food Sci Nutr, 58(16), 2768-2778. https://doi.org/10.1080/10408398.2017.134138 5

Bilik, V., Tihlárik, K. (1973). Reactions of saccharides catalyzed by molybdate ions. IX.* Epimerization of ketohexoses. Chemicke Zvesti, 28(1), 106-109. 
Chen, J., Zhu, Y., Fu, G., Song, Y., Jin, Z., Sun, Y., Zhang, D. (2016). High-level intra- and extracellular production of d-psicose 3-epimerase via a modified xylose-inducible expression system in Bacillus subtilis. J Ind Microbiol Biotechnol, 43(11), 1577-1591. https://doi.org/10.1007/s10295016-1819-6

Chen, X., Wang, W., Xu, J., Yuan, Z., Yuan, T., Zhang, Y., Liang, C., He, M., Guo, Y. (2017). Production of D-psicose from D-glucose by coexpression of D-psicose 3-epimerase and xylose isomerase. Ensyme Microb Tecbnol, 105: 18-23. https://doi.org/10.1016/j.enzmictec.2017.06.00 3

Dedania, S.R., Patel, M.J., Patel, D.M., Akhani, R.C., Patel, D.H. (2017). Immobilization on graphene oxide improves the thermal stability and bioconversion efficiency of D-psicose 3epimerase for rare sugar production. Ensyme Microb Technol, 107: 49-56. https://doi.org/10.1016/j.enzmictec.2017.08.00 3

Dedania, S.R., Patel, V.K., Soni, S.S., Patel, D.H. (2020). Immobilization of Agrobacterium tumefaciens D-psicose 3-epimerase onto titanium dioxide for bioconversion of rare sugar. Ensyme Microb Technol, 140: 109605. https://doi.org/10.1016/j.enzmictec.2020.10960 5

Do, G.Y., Kwon, E.Y., Kim, Y.J., Han, Y., Kim, S.B., Kim, Y.H., Choi, M.S. (2019). Supplementation of non-dairy creamer-enriched high-fat diet with d-allulose ameliorated blood glucose and body fat accumulation in C57BL/6J mice. Appl Sci, $9(13)$ : 2750. https://doi.org/10.3390/app9132750

Doner, L.W. (1979). Isomerization of D-fructose by base: Liquid-chromatographic evaluation and the isolation of D-psicose. Carbohydr Res, 70(2): 209-216.

FDA. (2017). GRAS Notice (GRN) No. 693. Encyclopedia of Toxicology, (693), 417-420. https://doi.org/10.1016/b0-12-3694000/00448-8

FDA. (2019). The declaration of allulose and calories from allulose on nutrition and supplement facts labels: guidance for industry. www.fda.gov/media/123342/download (Accessed: 10 December 2020).

Gil-Campos, M., San José González, M.A., Díaz Martín, J.J. (2015). Use of sugars and sweeteners in children's diets. Recommendations of the Nutrition Committee of the Spanish Association of Paediatrics. Anales de Pediatría (English Edition), 83(5), 353.e1-353.e7. https://doi.org/10.1016/ j.anpede.2015.10.002

Hadipernata, M., Ogawa, M., Hayakawa, S. (2016). Effect of D-allulose on rheological properties of chicken breast sausage. Poult Sci, 95(9): 2120-2128. https://doi.org/10.3382/ ps/pew143

Hadipernata, M., Ogawa, M., Hayakawa, S. (2017). Improved rheological properties of chicken egg frozen gels fortified by Dketohexoses. J Food Process Preservation, 41(5). https://doi.org/10.1111/jfpp.13184

Han, Y., Han, H. J., Kim, A.H., Choi, J.Y., Cho, S.J., Park, Y.B., Jung, U.J., Choi, M. S. (2016). Dallulose supplementation normalized the body weight and fat-pad mass in diet-induced obese mice via the regulation of lipid metabolism under isocaloric fed condition. Mol Nutr Food Res, 60(7): 1695-1706. https://doi.org/10.1002/ mnfr.201500771

Han, Y., Kwon, E.Y., Yu, M.K., Lee, S.J., Kim, H.J., Kim, S.B., Kim, Y.H., Choi, M.S. (2018). A preliminary study for evaluating the dosedependent effect of $\mathrm{D}$-allulose for fat mass reduction in adult humans: A randomized, double-blind, placebo-controlled trial. Nutrients, 10(2): nu10020160

Hashii, K., Hasegawa, T., Idegami, N., Kadota, M., Taniguchi, M., Toyama, T., Toyonaga, D. (2015). Rare Sugar. Discover Kagawa through English and Science, 40.

Hossain, A., Yamaguchi, F., Matsuo, T., Tsukamoto, I., Toyoda, Y., Ogawa, M., Nagata, Y., Tokuda, M. (2015). Rare sugar D-allulose: Potential role and therapeutic monitoring in maintaining obesity and type 2 diabetes mellitus. Pharm Ther, 155: 45-49. 
https://doi.org/10.1016/j.pharmthera.2015.08.0 04

Iida, T., Hayashi, N., Yamada, T., Yoshikawa, Y., Miyazato, S., Kishimoto, Y., Okuma, K., Tokuda, M., Izumori, K. (2010). Failure of D-psicose absorbed in the small intestine to metabolize into energy and its low large intestinal fermentability in humans. Metab Clin Exp, 59(2): 206-214. https://doi.org/10.1016/j.metabol.2009.07.018

Ilhan, E., Pocan, P., Ogawa, M., Oztop, M. H. (2020). Role of 'D-allulose' in a starch based composite gel matrix. Carbohydr Polym, 228: 115373.

j.carbpol.2019.115373

Itoh, H., Okaya, H., Khan, A.R., Tajima, S., Hayakawa, S., Izumori, K. (1994). Purification and characterization of D-tagatose 3-epimerase from Pseudomonas sp. ST-24 . Biosci Biotechnol Biochem, 58(12): 2168-2171. https://doi.org/ 10.1271/bbb.58.2168

Iwasaki, Y., Sendo, M., Dezaki, K., Hira, T., Sato, T., Nakata, M., Goswami, C., Aoki, R., Arai, T., Kumari, P., Hayakawa, M., Masuda, C., Okada, T., Hara, H., Drucker, D.J., Yamada, Y., Tokuda, M., Yada, T. (2018). GLP-1 release and vagal afferent activation mediate the beneficial metabolic and chronotherapeutic effects of D-allulose. Nat Commun, 9(1). https://doi.org/10.1038/s41467017-02488-y

Jia, M., Mu, W., Chu, F., Zhang, X., Jiang, B., Zhou, L.L., Zhang, T. (2014). A D-psicose 3epimerase with neutral $\mathrm{pH}$ optimum from Clostridium bolteae for D-psicose production: Cloning, expression, purification, and characterization. Appl Microbiol Biotechnol, 98(2): 717-725. https://doi.org/10.1007/s00253-0134924-8

Jiang, S., Xiao, W., Zhu, X., Yang, P., Zheng, Z., Lu, S., Jiang, S., Zhang, G., Liu, J. (2020). Review on D-Allulose: In vivo metabolism, catalytic mechanism, engineering strain construction, bioproduction technology. Front Bioeng Biotechnol, 8. https://doi.org/10.3389/fbioe.2020.00026

Juneja, A., Zhang, G., Jin, Y.S., Singh, V. (2019). Bioprocessing and technoeconomic feasibility analysis of simultaneous production of D-psicose and ethanol using engineered yeast strain KAM2GD. Bioresour Technol, 275: 27-34. https://doi.org/10.1016/j.biortech.2018.12.025

Kim, H.J., Hyun, E.K., Kim, Y.S., Lee, Y.J., Oh, D.K. (2006). Characterization of an Agrobacterium tumefaciens D-psicose 3-epimerase that converts D-fructose to D-psicose. Appl Environ Microbiol, 72(2): 981-985. https://doi.org/10.1128/ AEM.72.2.981-985.2006

Kim, H., Park, C., Sa, S., Case, I., Li, C., Gao, Y., Wang, H., Tian, J. (2019). A study of D-alluloseassociated reproductive toxicity in rats. Food Chem Toxicol, 131: 110548. https://doi.org/10.1016/ j.fct.2019.05.056

Kimura, T., Kanasaki, A., Hayashi, N., Yamada, T., Iida, T., Nagata, Y., Okuma, K. (2017). Dallulose enhances postprandial fat oxidation in healthy humans. Nutrition, 43-44: 16-20. https://doi.org/10.1016/j.nut.2017.06.007

Li, C., Zhang, C., Lin, J., Gao, L., Lin, H., Lin, J. (2018a). Enzymatic fructose removal from Dpsicose bioproduction model solution and the system modeling and simulation. J Chem Technol Biotechnol, 93(5): 1249-1260. https://doi.org/ 10.11164/jjsps.3.2_349_1

Li, C., Lin, J., Guo, Q., Zhang, C., Du, K., Lin, H., Lin, J. (2018b). D-psicose 3-epimerase secretory overexpression, immobilization, and d-psicose biotransformation, separation and crystallization. J Chem Technol Biotechnol, 93(2): 350-357. https://doi.org/10.1002/jctb.5360

Li, S., Chen, Z., Zhang, W., Guang, C., Mu, W. (2019). Characterization of a D-tagatose 3epimerase from Caballeronia fortuita and its application in rare sugar production. Int J Biol Macromol, 138: 536-545. https://doi.org/ 10.1016/j.ijbiomac.2019.07.112

Li, Z., Li, Y., Duan, S., Liu, J., Yuan, P., Nakanishi, H., Gao, X.D. (2015). Bioconversion of D-glucose to D-psicose with immobilized Dxylose isomerase and D-psicose 3-epimerase on Saccharomyces cerevisiae spores. J Ind Microbiol Biotechnol, 42(8): 1117-1128. https://doi.org/ 10.1007/s10295-015-1631-8 
Mao, S., Cheng, X., Zhu, Z., Chen, Y., Li, C., Zhu, M., Liu, X., Lu, F., Qin, H.M. (2020). Engineering a thermostable version of $\mathrm{D}$-allulose 3-epimerase from Rhodopirellula baltica via site-directed mutagenesis based on B-factors analysis. Enayme Microb Technol, 132: 109441. https://doi.org/ 10.1016/j.enzmictec.2019.109441

Matsuo, T., Izumori, K. (2006). Effects of dietary $\mathrm{D}$-psicose on diurnal variation in plasma glucose and insulin concentrations of rats. Biosci Biotechnol Biochem, 70(9): 2081-2085. https://doi.org/ 10.1271/bbb.60036

Matsuo, T., Tanaka, T., Hashiguchi, M., Izumori, K., Suzuki, H. (2002). Effects of oral acute administration and subchronic feeding of several levels of D-psicose in rats. J Nutr Sci Vitaminol, 48(6): 512-516. https://doi.org/10.3177/ jnsv.48.512

McDonald, E.J. (1967). A new synthesis of Dpsicose (D-ribo-hexulose). Carbobydr Res, 5(1): 106-108. https://doi.org/10.1016/00086215(67)85014-6

Mu, W., Chu, F., Xing, Q., Yu, S., Zhou, L., Jiang, B. (2011). Cloning, expression, and characterization of a D-psicose 3-epimerase from Clostridium cellulolyticum H10. J Agric Food Chem, 59(14): 7785-7792. https://doi.org/10.1021/ jf201356q

$\mathrm{Mu}$, W., Hassanin, H.A.M., Zhou, L., Jiang, B. (2018). Chemistry behind rare sugars and bioprocessing. J Agric Food Chem, 66(51): 1334313345. https://doi.org/10.1021/acs.jafc.8b06293

Mu, W., Yu, L., Zhang, W., Zhang, T., Jiang, B. (2015). Isomerases for biotransformation of Dhexoses. Appl Microbiol Biotechnol, 99(16): 65716584. https://doi.org/10.1007/s00253-0156788-6

Mu, W., Zhang, W., Fang, D., Zhou, L., Jiang, B., Zhang, T. (2013). Characterization of a Dpsicose-producing enzyme, D-psicose 3epimerase, from Clostridium sp. Biotechnol Lett, 35(9): 1481-1486. https://doi.org/10.1007/ s10529-013-1230-6

Nagata, Y., Kanasaki, A., Tamaru, S., Tanaka, K. (2015). D-psicose, an epimer of D-fructose, favorably alters lipid metabolism in SpragueDawley rats. J Agric Food Chem, 63(12): 3168-3176. https://doi.org/10.1021/jf502535p

O’Charoen, S., Hayakawa, S., Ogawa, M. (2015). Food properties of egg white protein modified by rare ketohexoses through Maillard reaction. Int J Food Sci Technol, 50(1): 194-202. https://doi.org/10.1111/ijfs.12607

Oshima, H., Kimura, I., Izumori, K. (2006). Psicose contents in various food products and its origin. Food Sci Technol Res, 12(2): 137-143. https://doi.org/10.3136/fstr.12.137

Özgür, M., Uçar, A. (2019). Karbonhidrat ve Yağ Metabolizmasinda D-alluloz (D-psikoz). Düzce Üniversitesi Sağhl. Bilimleri Enstitüsü Dergisi, 9(3), 188-195. https://doi.org/10.33631/ duzcesbed.469828

Park, C.S., Kim, T., Hong, S.H., Shin, K.C., Kim, K.R., Oh, D. K. (2016). D-allulose production from $\mathrm{D}$-fructose by permeabilized recombinant cells of Corynebacterium glutamicum cells expressing D-allulose 3-epimerase Flavonifractor plautii. PLOS ONE, 11(7). https://doi.org/10.1371/ journal.pone.0160044

Patel, S.N., Sharma, M., Lata, K., Singh, U., Kumar, V., Sangwan, R.S., Singh, S.P. (2016). Improved operational stability of D-psicose 3epimerase by a novel protein engineering strategy, and $\mathrm{d}$-psicose production from fruit and vegetable residues. Bioresour Technol, 216: 121-127. https://doi.org/10.1016/j.biortech.2016.05.053

Patel, S.N., Singh, V., Sharma, M., Sangwan, R.S., Singhal, N.K., Singh, S.P. (2018). Development of a thermo-stable and recyclable magnetic nanobiocatalyst for bioprocessing of fruit processing residues and $\mathrm{D}$-allulose synthesis. Bioresour Technol, 247: 633-639. https://doi.org/10.1016/j.biortech.2017.09.112

Qi, Z., Zhu, Z., Wang, J.W., Li, S., Guo, Q., Xu, P., Lu, F., Qin, H.M. (2017). Biochemical analysis and the preliminary crystallographic characterization of D-tagatose 3-epimerase from Rhodobacter sphaeroides. Microb Cell Fact, 16(1): 1-9. https://doi.org/10.1186/s12934-017-0808-4 
Ran, G., Tan, D., Zhao, J., Fan, F., Zhang, Q., Wu, X., Fan, P., Fang, X., Lu, X. (2019). Functionalized polyhydroxyalkanoate nano-beads as a stable biocatalyst for cost-effective production of the rare sugar D-allulose. Bioresour Technol, 289: 9-18. https://doi.org/10.1016/ j.biortech.2019.121673

Shintani, T., Yamada, T., Hayashi, N., Iida, T., Nagata, Y., Ozaki, N., Toyoda, Y. (2017). Rare sugar syrup containing D-allulose but not highfructose corn syrup maintains glucose tolerance and insulin sensitivity partly via hepatic glucokinase translocation in Wistar rats. $J$ Agric Food Chem, 65(13): 2888-2894. https://doi.org/10.1021/acs.jafc.6b05627

Song, Y., Nguyen, Q.A., Wi, S.G., Yang, J., Bae, H.J. (2017a). Strategy for dual production of bioethanol and D-psicose as value-added products from cruciferous vegetable residue. Bioresour Technol, 223: 34-39. https://doi.org/10.1016/j.biortech.2016.10.021

Song, Y., Oh, C., Bae, H.J. (2017b). Simultaneous production of bioethanol and value-added Dpsicose from Jerusalem artichoke (Helianthus tuberosus L.) tubers. Bioresour Technol, 244: 10681072. https://doi.org/10.1016/j.biortech. 2017.08.079

Takeshita, K., Suga, A., Takada, G., Izumori, K. (2000). Mass production of D-psicose from Dfructose by a continuous bioreactor system using immobilized D-tagatose 3-epimerase. J Biosci Bioeng, 90(4): 453-455. https://doi.org/10.1016/ S1389-1723(01)80018-9

Tseng, W.C., Chen, C.N., Hsu, C.T., Lee, H.C., Fang, H.Y., Wang, M.J., Wu, Y.H., Fang, T.Y. (2018). Characterization of a recombinant Dallulose 3-epimerase from Agrobacterium sp. ATCC 31749 and identification of an important interfacial residue. Int J Biol Macromol, 112(400): 767-774. https://doi.org/10.1016/j.ijbiomac. 2018.02.036

Van Laar, A.D.E., Grootaert, C., Van Camp, J. (2020). Rare mono- and disaccharides as healthy alternative for traditional sugars and sweeteners? Crit Rev Food Sci Nutr, 1-29. https://doi.org/10.1080/10408398.2020.174396 6

Wee, M., Tan, V., Forde, C. (2018). A comparison of psychophysical dose-response behaviour across 16 sweeteners. Nutrients, 10(11), 1-16. https://doi.org/10.3390/nu10111632

Yang, P., Zhu, X., Zheng, Z., Mu, D., Jiang, S., Luo, S., Wu, Y., Du, M. (2018). Cell regeneration and cyclic catalysis of engineered Kluyveromyces marxianus of a D-psicose-3-epimerase gene from Agrobacterium tumefaciens for D-allulose production. World J Microbiol Biotechnol, 34(5). https://doi.org/10.1007/s11274-018-2451-6

Yoshihara, A., Kozakai, T., Shintani, T., Matsutani, R., Ohtani, K., Iida, T., Akimitsu, K., Izumori, K., Gullapalli, P.K. (2017). Purification and characterization of $\mathrm{D}$-allulose 3-epimerase derived from Arthrobacter globiformis M30, a GRAS microorganism. J Biosci Bioeng, 123(2): 170-176. https://doi.org/10.1016/j.jbiosc.2016.09.004

Zeng, Y., Dou, D., Zhang, Y., Zhang, L., Sun, Y. (2015). Rare sugars and antioxidants in Itea virginica, Itea oblonga Hand.-Mazz., and Itea yunnanensis franch leaves. In J Food Prop, 18(11): 2549-2560. https://doi.org/10.1080/ 10942912.2014.917099

Zhang, J., Xu, C., Chen, X., Ruan, X., Zhang, Y., $\mathrm{Xu}, \mathrm{H}$., Guo, Y. (2020). Engineered Bacillus subtilis harbouring gene of $\mathrm{D}$-tagatose 3-epimerase for the bioconversion of D-fructose into D-psicose through fermentation. Ensyme Microb Technol, 136: 109531. https://doi.org/10.1016/ j.enzmictec.2020.109531

Zhang, L., Mu, W., Jiang, B., Zhang, T. (2009). Characterization of D-tagatose-3-epimerase from Rhodobacter sphaeroides that converts $\mathrm{D}$-fructose into D-psicose. Biotechnol Lett, 31(6): 857-862. https://doi.org/10.1007/s10529-009-9942-3

Zhang, W., Fang, D., Xing, Q., Zhou, L., Jiang, B., Mu, W. (2013a). Characterization of a novel metal-dependent D-psicose 3-epimerase from Clostridium scindens 35704. PLoS ONE, 8(4): 1-9. https://doi.org/10.1371/journal.pone.0062987

Zhang, W., Fang, D., Zhang, T., Zhou, L., Jiang, B., Mu, W. (2013b). Characterization of a metal- 
dependent D-psicose 3-epimerase from a novel strain, Desmospora sp. 8437. J Agric Food Chem, 61(47): 11468-11476. https://doi.org/10.1021/ jf4035817

Zhang, W., Li, H., Zhang, T., Jiang, B., Zhou, L., $\mathrm{Mu}, \mathrm{W}$. (2015). Characterization of a D-psicose 3epimerase from Dorea sp. CAG317 with an acidic $\mathrm{pH}$ optimum and a high specific activity. $J$ Mol Catal B Ensym, 120: 68-74. https://doi.org/ 10.1016/j.molcatb.2015.05.018

Zhang, W., Zhang, T., Jiang, B., Mu, W. (2016). Biochemical characterization of a D-psicose 3epimerase from Treponema primitia ZAS-1 and its application on enzymatic production of Dpsicose. J Sci Food Agric, 96(1): 49-56. https://doi.org/10.1002/jsfa.7187

Zhang, W., Zhang, T., Jiang, B., Mu, W. (2017). Enzymatic approaches to rare sugar production. Biotechnol Adv, 35(2): 267-274. https://doi.org/ 10.1016/j.biotechadv.2017.01.004
Zhang, W., Zhang, Y., Huang, J., Chen, Z., Zhang, T., Guang, C., Mu, W. (2018). Thermostability improvement of the D-allulose 3-epimerase from Dorea sp. CAG317 by sitedirected mutagenesis at the interface regions. $J$ Agric Food Chem, 66(22): 5593-5601. https://doi.org/10.1021/acs.jafc.8b01200

Zhu, Y., Men, Y., Bai, W., Li, X., Zhang, L., Sun, Y., Ma, Y. (2012). Overexpression of D-psicose 3-epimerase from Ruminococcus sp. in Escherichia coli and its potential application in D-psicose production. Biotechnol Lett, 34(10): 1901-1906. https://doi.org/10.1007/s10529-012-0986-4

Zhu, Z., Li, C., Liu, X., Gao, D., Wang, X., Tanokura, M., Qin, H.M., Lu, F. (2019). Biochemical characterization and biocatalytic application of a novel D-tagatose 3-epimerase from: Sinorbizobium sp. RSC Advances, 9(6): 29192927. https://doi.org/10.1039/c8ra10029b 